\title{
Incentive Contracts and Hedge Fund Management: A Numerical Evaluation Procedure
}

\author{
by \\ James E. Hodder \\ and \\ Jens Carsten Jackwerth
}

September 15, 2003

James Hodder is from the University of Wisconsin-Madison, Finance Department, School of Business, 975 University Avenue, Madison, WI 53706, Tel: 608-262-8774, Fax: 608-265-4195, jhodder@bus.wisc.edu. Jens Jackwerth is from the University of Konstanz, Department of Economics, PO Box D-134, 78457 Konstanz, Germany, Tel.: +49-(0)7531-88-2196, Fax: +49(0)7531-88-3120, jens.jackwerth@uni-konstanz.de. We would like to thank Günter Franke, Sebastien Galy, Stewart Hodges, Pierre Mella-Barral, Mark Rubinstein, Paolo Sodini, Fabio Trojani, and seminar participants at Stockholm School of Economics, University of Konstanz, University Svizzera Italiana, and University of Zurich for helpful comments on an earlier paper entitled "Pricing Derivatives on a Controlled Stochastic Process: A Simplified Approach". 


\title{
Incentive Contracts and Hedge Fund Management: A Numerical Evaluation Procedure
}

\begin{abstract}
The behavior of a hedge-fund manager naturally depends on her compensation scheme, her preferences, and constraints on her risk-taking. We propose a numerical method which can be used to analyze the impact of these influences. The model leads to several interesting and novel results concerning her risk-taking and other managerial decisions. We are able to relate our results to partial results in the literature and show how they fit in a more general context. We also allow the manager to voluntarily shutdown the fund as well as enhancing the fund's Sharpe Ratio through additional effort. Both these extensions generate additional insights. Throughout the paper, we find that even slight changes in the compensation structure or the extent of managerial discretion can lead to drastic changes in her risk-taking.
\end{abstract}




\section{Incentive Contracts and Hedge Fund Management: A Numerical Evaluation Procedure}

Several recent papers examine effects of incentive compensation on the optimal dynamic investment strategies of money managers. Carpenter (2000) and Basak, Pavlova, and Shapiro (2003) focus directly on this issue. ${ }^{1}$ Goetzmann, Ingersoll, and Ross (2003) focus primarily on valuing claims (including management fees) on a hedge fund's assets. Most of that paper assumes the fund follows a constant investment policy; however, one section briefly explores managerial control of fund risk. These three papers all generate analytic solutions using equivalent martingale frameworks in continuous time. Interestingly, they generate seemingly conflicting results regarding the manager's optimal risk-taking behavior.

We pursue a different tack and develop a numerical approach to determine the manager's optimal investment strategy. In the process, we are able to shed light on the differing results in the above papers as we relate them to our own model. Perhaps not surprisingly, it turns out that these papers have differences (sometimes rather subtle) in how they model the manager's compensation structure. More surprising is that some seemingly minor differences have dramatic impacts on optimal risk taking by the manager.

Our setting is that of a hedge fund controlled by a single risk-averse manager. We choose this setting rather than a mutual fund because there are many fewer constraints on managerial behavior. Our compensation structure is similar to that in Goetzmann, Ingersoll, and Ross (hereafter, GIR) and includes both a proportional fee and an incentive based on exceeding a "high-water mark." Unlike GIR, our focus is on determining the optimal investment strategy

${ }^{1}$ There are also related papers by Basak, Shapiro, and Teplá (2002), who investigate risk taking when there is benchmarking, and by Ross (forthcoming), who decomposes risk taking according to three underlying causes. 
from the perspective of an expected utility maximizing manager. In that respect, our paper is closer to the focus of Carpenter as well as Basak, Pavlova, and Shapiro (hereafter, BPS).

Recognizing that a manager will control the hedge fund's investments, altering them through time, means that the hedge fund's value follows a controlled process. There is an important analogy with Merton (1969) which examines the optimal investment strategy for an expected utility maximizing individual who controls his own investment portfolio. ${ }^{2}$ In Merton's model with constant relative risk aversion, the optimal fraction of wealth invested in the risky security is a constant through time. Although optimally controlled, the associated wealth process evolves just like a standard geometric Brownian motion. Under some simple circumstances, the hedge fund manager will follow such a strategy. However, it will frequently be the case that the manager's optimal strategy will differ substantially from the Merton solution. In that case, the Merton result represents a useful base case for assessing how the fund manager's behavior differs from what would be preferred by an unconstrained outside investor with the same utility function.

Note that the manager's compensation is a payoff whose value depends on fund performance. Hence, we are effectively valuing a derivative on a controlled stochastic process. Consequently, the basic approach we develop can be applied to other situations where a portfolio return process is controlled by a utility maximizing manager. With some added constraints, a mutual fund manager clearly fits this description as does a currency trader at a bank. In a more approximate manner, we can think of a firm being controlled by an individual manager (the CEO). A useful comparison is Merton (1974), where risky debt is valued based on an exogenous underlying process for the firm's asset value. We are suggesting an alternative perspective where that asset value process is controlled via investment and hedging decisions in a manner analogous to an investment portfolio. From that perspective, not only risky debt but any

2 Merton's work in turn is based on Markowitz's (1959) dynamic programming approach and Mossin's (1968) implementation of that idea in discrete time. 
derivative based on firm value is (implicitly) based on a controlled process. Hence, the basic valuation technology developed in this paper has numerous potential applications.

In the next section, we present the basic model and briefly describe the solution methodology (more details are in the Appendix). Section II provides numerical results for a standard set of parameters. We actually begin with a simplified version of the model which allows us to build intuition using the Merton (1969) results. Then we add pieces of the compensation structure and examine the effects on managerial behavior. Section III compares our results with those from Carpenter, GIR, and BPS. This is a useful exercise which allows us to see that these papers are effectively looking at different parts of a larger picture. It also helps our understanding of how different pieces of the compensation structure interact to influence risk taking in various regions of the state space. Sections IV and V deal with two additional aspects of hedge-fund management. There, we allow the manager to voluntarily shut down the fund. If this occurs, it would typically be at a fund value well below the high-water mark. Shutting down avoids the costs of running the fund, while allowing the manager to take up a new job or, perhaps, start a new fund (with a reset high-water mark, which makes earning an incentive fee much more likely). This voluntary shut-down alternative is modeled in Section IV as an American option. In Section $\mathrm{V}$, we also allow the manager to choose her effort level which alters the fund's return distribution. The manager suffers a disutility from increased effort, and we investigate her optimal strategy for balancing the costs and benefits of effort exertion. Section VI concludes.

\section{The Basic Model and Solution Methodology}

Consider the problem of a hedge fund manager's optimal allocation of portfolio value into a risky and a riskless investment opportunity. Assume the manager has a compensation contract 
paying a $2 \%$ annual rate on the fund's value (Net Asset Value) plus $20 \%$ of the amount by which that value exceeds a "high-water mark" at the end of the period. Such a fee structure is typical for a hedge fund. ${ }^{3}$ We are treating the manager as having full control and receiving all the fees earned by the fund. Frequently, a hedge fund manager has a substantial personal investment in the fund. Fung and Hsieh (1999) suggest that this "inhibits excessive risk taking." For our analysis, we will assume the manager owns $10 \%$ of the fund. That level of ownership, or more, is certainly plausible for a medium-sized hedge fund. A large fund with assets exceeding a billion dollars would likely have a substantially smaller percentage but still a non-trivial managerial ownership stake.

We use a high-water mark that is indexed so that it grows at the riskless interest rate during the evaluation period (a fairly common structure). Letting $\mathrm{H}_{0}$ denote the high water mark at the beginning of an evaluation period with length $\mathrm{T}$, we have $\mathrm{H}_{0} \mathrm{e}^{\mathrm{rT}}$ at the period's end. If the fund performs poorly, it may be shut down. The simplest approach is to have a prespecified liquidation boundary. Our basic valuation procedure uses this approach with the fund being liquidated if its value falls to $50 \%$ of the current high-water mark. ${ }^{4}$ Using $\Phi_{t}$ to denote the level of the liquidation boundary at time time t, we set $\Phi_{\mathrm{t}}=0.5 \mathrm{H}_{0} \mathrm{e}^{\mathrm{rt}}$.

The risky investment's value evolves as:

$$
d \theta=\mu \theta d t+\sigma \theta d z
$$

\footnotetext{
${ }^{3}$ See for example, Fung and Hsieh (1999) for a description of incentive fees as well as a variety of additional background information on hedge funds.

${ }^{4}$ Apparently such liquidation boundaries are sometimes contractual and sometimes based on an unwritten understanding between the fund management and outside investors. Goetzmann, Ingersoll, and Ross (2001) also use a prespecified liquidation boundary based on the high water mark.
} 
Think of this as a proprietary technology which can be utilized by the fund manger but is not fully understood by outside investors (and hence not replicable by them). The riskfree investment grows at the constant rate $\mathrm{r}$ :

$$
d B=r B d t
$$

Let $\mathrm{X}$ denote the current value of the fund's assets and $\alpha$ the fraction of that value allocated to the risky investment. We allow the manager to control $\alpha$, which is short for $\alpha(X, t)$. Thus, the fund's value evolves as:

$$
\begin{aligned}
d X & =\alpha X \frac{d \theta}{\theta}+(1-\alpha) X \frac{d B}{B} \\
& =\alpha X \mu d t+(1-\alpha) X r d t+\alpha X \sigma d z
\end{aligned}
$$

Instantaneous changes in $\log \mathrm{X}$ are then normally distributed.

We assume the manager seeks to maximize expected utility of terminal wealth $\mathrm{W}_{\mathrm{T}}$ and has a utility function that exhibits constant relative risk aversion $\gamma$ (an assumption that can readily be relaxed):

$$
U\left(W_{T}\right)=\frac{W_{T}^{1-\gamma}}{1-\gamma}
$$

The manager is compensated based on the fund's performance if it is not liquidated prior to time $\mathrm{T}$, which is measured in years. We assume the manager has no outside wealth but rather owns a fraction of the fund, with her fractional ownership denoted by $a=10 \%$. On the remaining (1-a) of fund assets, she earns a management fee at a rate of $b=2 \%$ annually plus an incentive fee of 
$\mathrm{c}=20 \%$ on the amount by which $\mathrm{X}_{\mathrm{T}}$ exceeds the high-water mark. If the value of the fund has remained above the liquidation boundary prior to date $\mathrm{T}$, her wealth at $\mathrm{T}$ is:

$$
\begin{aligned}
W_{T} & =a X_{T}+(1-a) b T X_{T}+(1-a) c\left(X_{T}-H_{0} e^{r T}\right)^{+} \\
& =(a-a b T+b T) X_{T}+(1-a) c\left(X_{T}-H_{0} e^{r T}\right)^{+}
\end{aligned}
$$

As indicated in (5), the manager's compensation if the fund doesn't liquidate is equivalent to a fractional share plus a fractional call option struck at the high-water mark $\mathrm{H}_{0} \mathrm{e}^{\mathrm{rT}}$. We will refer to this call as the incentive option.

Now consider the manager's compensation if the fund value hits the lower (liquidation) boundary prior to time T. Suppose the fund's value hits that boundary at time $\tau$, with $0 \leq \tau \leq \mathrm{T}$; and it is immediately liquidated. For the moment, we assume no dead weight cost to liquidation but do recognize that, in a discrete-time setting, the fund may cross the barrier and have $\mathrm{X}_{\tau}<\Phi_{\tau}$. Our base case assumption will be that the manager recovers her personal investment aX $\mathrm{X}_{\tau}$ plus a prorated portion of the management fee $\tau(1-\mathrm{a}) \mathrm{b} \Phi_{\tau}$. This total is reinvested until $\mathrm{T}$ at the riskless interest rate. This last step is because we have defined the manager's utility in terms of time T wealth. This results in:

$$
\mathrm{W}_{\mathrm{T}}=\mathrm{aX}_{\tau} \mathrm{e}^{\mathrm{r}(\mathrm{T}-\tau)}+0.5(1-\mathrm{a}) \mathrm{b} \tau \mathrm{H}_{0} \mathrm{e}^{\mathrm{rT}} \quad \text { for } 0 \leq \tau \leq T
$$

where the value of the first term depends on when the fund reaches the boundary and by how much it crosses that boundary. Note, however, that once the boundary has been reached or crossed, we know $\mathrm{X}_{\tau}$ and $\tau$ so the terminal payoff in (6) is certain. An obvious alternative to (6), which we will also consider, is that the manager receives a smaller amount due either to some liquidation costs or an explicit penalty built into the fee structure. In any case, we will 
refer to the payment the manager receives if the fund hits the liquidation boundary as her severance compensation.

As we shall see shortly, the lower (liquidation) boundary plays an important role in determining the manager's optimal portfolio allocations over time. In a different context, such as a mutual fund, we could think of the lower boundary as representing a performance level at which the manager would be replaced (fired) and receive some sort of severance package. Failure to consider such a boundary when modeling managerial behavior leads to very different and potentially seriously misleading results.

It is instructive to compare the basic structure of our model with Merton (1969). In Merton's model, an individual (analogous to our manager) dynamically chooses the optimal allocation of available funds between shares and the riskless asset. In the case where there is no intermediate consumption (between 0 and $\mathrm{T}$ ), she chooses that investment strategy to maximize her expected utility of terminal wealth $\left(\mathrm{W}_{\mathrm{T}}\right)$. This matches the situation of our manager if she had no incentive option and there wasn't a liquidation boundary. We know from Merton that the optimal alpha is constant under those assumptions for an individual with our utility function.

Simply adding the liquidation boundary to Merton's model effectively turns the individual's share position into a knockout call with a rebate equal to the severance compensation of equation (6). In addition, the incentive fee adds another call option with a higher strike price (at the high-water mark). Either of these complications alters the optimal control (alpha), which creates substantial computational issues. To illustrate, consider the standard binomial model for derivative pricing. If alpha is constant, the binomial tree will have nodes that recombine. When alpha is not constant, the tree does not generally recombine. In addition, there is an optimization problem to be solved at each node - determining the optimal alpha. 
Our approach for dealing with these issues uses a discretization of the problem onto a finite-difference grid structure (more details are provided in the Appendix). From each grid point, we allow a multinomial forward move to a relatively large number of subsequent grid points (e.g. 121) at the next time step. We structure potential forward moves to land on grid points and calculate the associated probabilities using a discrete approximation of the normal distribution with a specified value for the control parameter alpha. With the log X step constant, this set of probabilities is identical at each grid point for a given alpha. Using a discrete set of alpha values, this allows us to create a matrix of probabilities with a probability vector for each potential alpha value.

At each terminal grid point, we calculate the manager's payoff and the associated utility. We then step backwards in time to T- $\Delta \mathrm{t}$. At each grid point within that time step, we calculate the expected utilities for all alpha levels in our discrete choice set. We choose the highest of those expected utilities as the optimal indirect utility for that grid point and denote its value as $\mathrm{J}(\mathrm{X}, \mathrm{T}-\Delta \mathrm{t})$. We record $\mathrm{J}(\mathrm{X}, \mathrm{T}-\Delta \mathrm{t})$ and the associated optimal alpha for each grid point within that time step and then loop backward in time, repeating this process through all time steps. This generates the indirect utility surface and optimal alpha values for our entire grid. Formally:

$$
J_{T}=U_{T} ; \quad J_{t}=E\left[J_{t+\Delta t}\right] \quad \text { where } \mathrm{t}=0, \Delta t, 2 \Delta t, \ldots, T-\Delta t
$$

\section{Some Illustrative Results}

We will frequently refer to a standard set of parameters as displayed in Table 1, which we will use as our reference case. The horizon is three months with portfolio revisions in 60 time steps, roughly once per trading day. For this reference case, the starting fund value of 1.00 equals the current high-water mark. We can think of the risky technology (e.g. convergence trades) 
employed by the hedge fund as a risky investment. On an unlevered basis, we assume that investment has a mean return of $7 \%$ and a volatility of $5 \%$. The riskless asset yields $5 \%$. This combination of mean returns and volatility would be consistent with a market-neutral strategy and implies a Sharpe Ratio of 0.40 , which seems reasonable in light of the results reported in Brown, Goetzmann, and Ibbotson (1999). We space 600 log steps between the lower (knockout) boundary and the initial X level. There are a further 600 steps above the initial X level before reaching the upper boundary. Beyond this artificial upper boundary, we simply use a version of the Merton (1969) optimal solution without consumption since the influences of the liquidation boundary and the incentive option are no longer felt.

Table 1

Standard Parameters

$\begin{array}{llllll}\text { Time to maturity } & \mathrm{T} & 0.25 & \text { Interest rate } & \mathrm{r} & 0.05 \\ \text { Log value steps below/above } \mathrm{X}_{0} & & 600 / 600 & \text { Initial fund value } & \mathrm{X}_{0} & 1.00 \\ \text { Risk aversion coefficient } & \gamma & 4 & \text { Mean } & \mu & 0.07 \\ \text { Number of time steps } & \mathrm{n} & 60 & \text { Volatility } & \sigma & 0.05 \\ \text { High water mark } & \mathrm{H}_{0} & 1.00 & \text { Incentive fee rate } & \mathrm{c} & 0.20 \\ \text { Exit boundary at t }=0 & \Phi_{0} & 0.50 & \text { Basic fee rate } & \mathrm{b} & 0.02 \\ \text { Manager's share ownership } & \mathrm{a} & 0.10 & & & \end{array}$

Future nodes for the Normal approx. $1+2 \times 60=121$

Log X step $\quad(\log (1 / 0.5)) / 600 \approx 0.001155$

Before displaying results for our reference case, it is useful to build some intuition by examining a sequence of simpler situations. If we eliminate the liquidation boundary and the incentive option (struck at the high water mark), we effectively have the case analyzed in Merton (1969) where the manager has a linear compensation in fund value and the optimal alpha is constant. Using Merton's results with our standard parameters, the optimal alpha is: 


$$
\alpha^{*}=\frac{(\mu-r)}{\gamma \sigma^{2}}=2 .
$$

In other words, the optimal alpha surface would be flat at the level 2.

We now add the liquidation or knockout barrier. The manager's optimal alpha levels are depicted in Figure 1 for our standard parameters except for setting $\mathrm{a}=\mathrm{c}=0$. That is, the manager has no ownership in the fund nor an incentive option. The manager exhibits essentially four different areas of economic behavior. Two of these areas are intuitively rather straightforward. The "Merton Flats" to the right in the figure is an area where the manager's optimal alpha recedes to the continuous time Merton solution, which in our case is 2 . This represents an area where fund value is far enough from the knockout barrier (given the time left to $\mathrm{T})$ that the barrier plays essentially no role in her decision making. 
Figure 1. Optimal Alpha Surface with No Incentive Option and with No Share Ownership of the Manager.

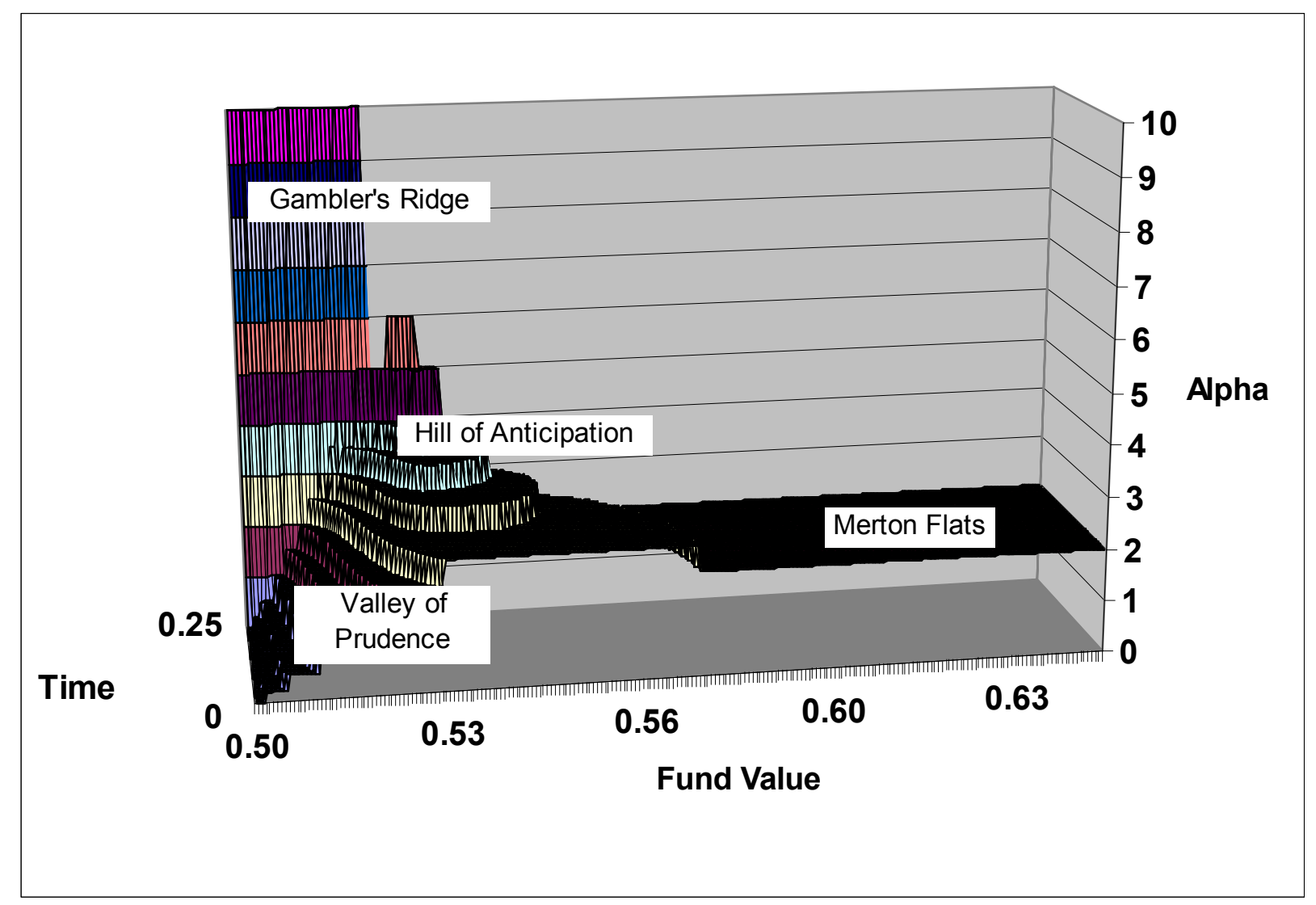

"Gambler's Ridge" in the far left corner of Figure 1 is also not surprising. Here the manager is in a situation just prior to T that could be described as "heads I win and tails I don't lose very much." She is thus willing to gamble with a very large alpha. Due to excluding alpha values where we did not get a good approximation for the normal distribution, the maximum available alpha here is only 10 . Nevertheless, her gambling behavior is pronounced.

More interesting and perhaps more surprising are the "Valley of Prudence" toward the left boundary and the "Hill of Anticipation" toward the center of Figure 1. The Valley of Prudence can be interpreted as a region where the manager chooses an alpha only slightly above 
zero in order to dramatically reduce the chance of hitting the boundary at an early date. ${ }^{5}$ Hitting the boundary early incurs a cost since the manager can no longer improve on her severance compensation by managing the portfolio. Approaching the terminal date, the remaining potential for her gaining from continuing to manage the portfolio becomes progressively smaller. Eventually, the possible upside from a high-alpha bet comes to dominate the alternative of carefully managing the portfolio, as she encounters Gambler's Ridge.

The Hill of Anticipation is a novel area of managerial behavior that to our knowledge has not been previously documented. It occurs a few percent above the lower boundary and starts some two months before the end. Here, the manager increases the risk of the controlled process substantially but not in the indiscriminate manner of the Gambler's Ridge. She has more to lose and more time left to manage the fund than on the Gambler's Ridge area, and this moderates her behavior regarding alpha. Nevertheless, she finds it attractive to increase alpha above the Merton optimum since the potential loss is limited and the time to maturity is relatively short. If she is fortunate and her higher-alpha bet pays off with a large increase in $\mathrm{X}$, she heads toward Merton Flats. There the higher alpha level is too risky. So it gets revised downward. Hence, the Hill of Anticipation tails off to the right approaching Merton Flats. The Hill of Anticipation also tails off to the left, dropping into the Valley of Prudence where she prefers to wait until very close to T before undertaking the high-alpha bets associated with Gambler's Ridge.

Thus, introducing a knockout barrier causes the manager to follow an optimal strategy that is much richer than the constant alpha solution of the Merton model. A key factor in these results is the absence of dead-weight liquidation costs or some penalty which reduces the manager's severance compensation. Even a relatively small penalty that reduces her severance

\footnotetext{
5 Since we approximate the normal distributions very accurately, there is still some exceedingly small probability of crossing the boundary as long as alpha is not exactly zero. The manager does not entertain negative alpha strategies as these are risky and can thus hit the boundary. Moreover, their expected return is less than the riskfree rate.
} 
compensation can eliminate her gambling behavior both at the boundary and on the Hill of Anticipation. This is illustrated in Figure 2 using a 3\% penalty.

Figure 2. Optimal Alpha Surface with a 3\% Penalty for Hitting the Lower Boundary and No Incentive Option and No Share Ownership by the Manager.



We now consider results for our reference case using the set of parameters in Table 1 but still without share ownership by the manager. In effect, this adds an incentive option (struck at the high-water mark) to the manager's knockout call examined previously (with no penalty to the severance compensation). In Figure 3, we see the same features as in Figure 1 plus a new region of high alpha values, which we term Option Ridge. This region is centered just below the terminal high-water mark of $\mathrm{H}_{0} \mathrm{e}^{\mathrm{rT}}=1.0125$. Again the manager dramatically increases the fund's riskiness as she approaches the terminal date. Now the motivation is to increase the chance of 
finishing with her option substantially in the money. She thus increases the alpha considerably if the fund value is either somewhat below or slightly above the strike price.

There is a Merton Flats region between the Hill of Anticipation and Option Ridge. This is because the liquidation boundary is relatively far below the high-water mark. If the liquidation boundary is sufficiently close to the high-water mark, the incentive option starts to affect the Hill of Anticipation causing it to spread into Option Ridge and eliminating the Merton Flats region in between. There is also another Merton Flats region that is far to the right. To reach that upper Merton Flats, her incentive option has to be sufficiently deep in the money that it acts like a fractional share position. Gambler's Ridge and the Valley of Prudence are driven almost exclusively by the lower boundary and therefore do not change noticeably when an incentive option is added to the manager's compensation. ${ }^{6}$

${ }^{6}$ They appear compressed in Figure 3 due to the change of horizontal scale relative to Figure 1. 
Figure 3. Optimal Alpha Surface with Incentive Option and with No Share Ownership of the Manager.

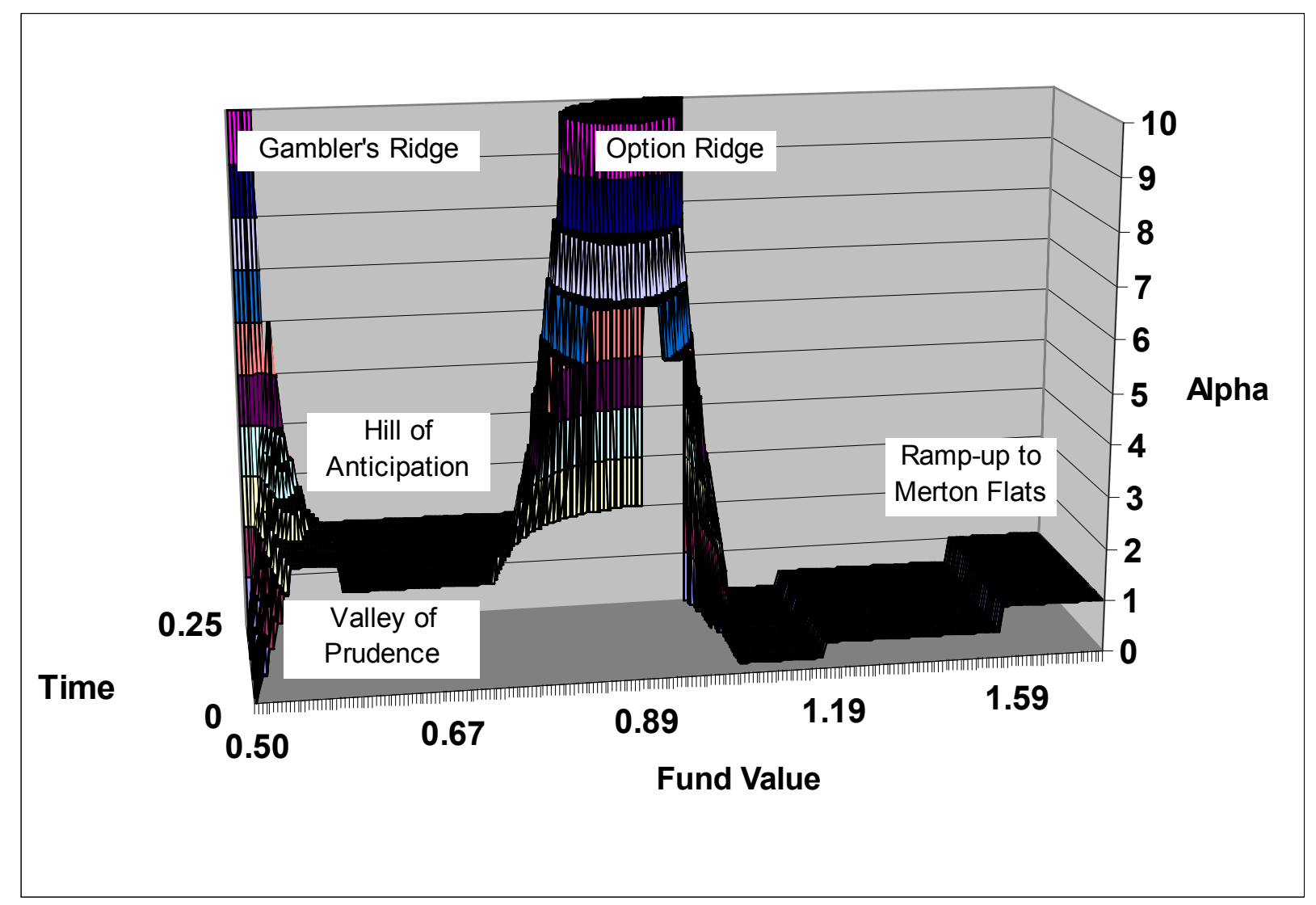

We now reintroduce the manager's share ownership $(a=10 \%)$ and examine the effect on her optimal alpha choice in Figure 4. The most dramatic differences between Figures 3 and 4 are that Gambler's Ridge almost disappears and the Hill of Anticipation does vanish. In previous figures, Gambler's Ridge and the Hill of Anticipation were induced by partial protection of the basic management fee ( $b=2 \%$ annually) when fund value hits the liquidation boundary. However, over a three-month interval, that management fee represents only $0.5 \%$ of fund value; and it's effects near the lower boundary are largely overwhelmed by the manager's $10 \%$ ownership stake. Consequently, this part of the picture is consistent with Fung and Hsieh's (1999) comment about managerial share ownership inhibiting excessive risk taking. Note that 
this qualitative result depends importantly on the degree of managerial ownership. Moreover, Option Ridge remains an area of very high alpha values, although somewhat narrower than previously. Above Option Ridge, the manager's optimal alpha does not drop quite as low as in Figure 3 and also ramps up faster towards a Merton Flats region at high fund values.

Figure 4: Optimal Alpha Surface with Incentive Option and with Share Ownership of the Manager.

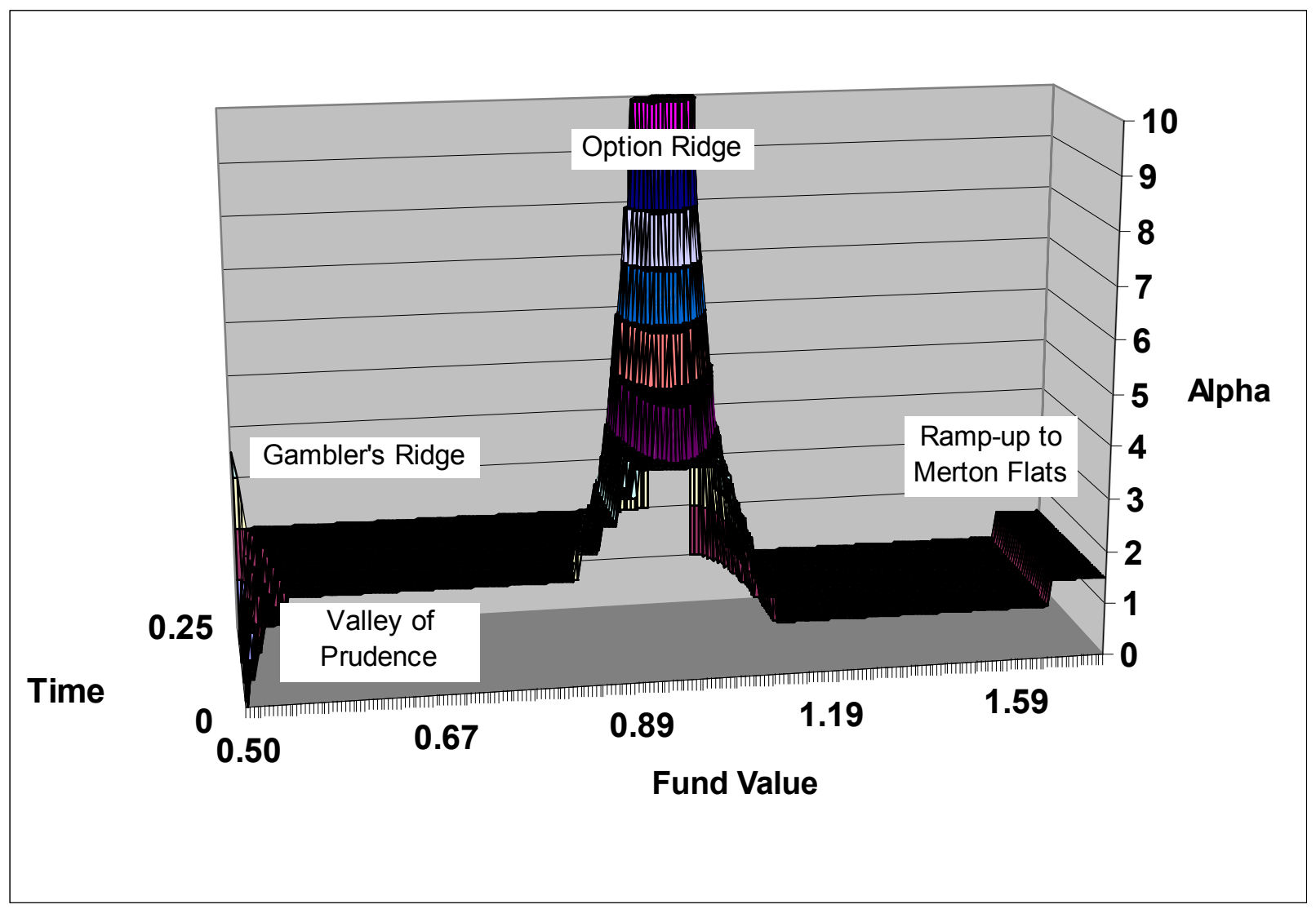

\section{Managerial Control and Risk Taking}

Recently there have been a number of papers examining the nature and effects of incentive compensation mechanisms for money managers. Although using different valuation 
technologies and somewhat different incentive structures, some of these papers have generated results which can be related to portions of our Figure 4. It's instructive to make those comparisons. It not only promotes a better understanding of how these papers fit together but also strengthens our knowledge of how shares, options, knockout barriers, and horizon times interact in influencing managerial behavior.

Carpenter (2000) utilizes an equivalent martingale technology to determine the optimal trading strategy for a risk-averse money manager whose compensation includes an option component. The manager seeks to maximize expected utility of terminal wealth, which is composed of a constant amount (external wealth and a fixed wage) plus a fractional call option on the assets under management with a strike price equal to a specified benchmark. There are substantial similarities to our model structure, with Carpenter's benchmark corresponding to our high-water mark at time T. There are also important differences. Carpenter's manager doesn't have a personal investment in the fund $(\mathrm{a}=0)$ and also doesn't earn a percentage fee on the funds under management $(b=0)$. These two differences remove the manager's fractional share ownership - see equation (5). Also, Carpenter does not have a knockout barrier where the fund is liquidated or the manager is fired for poor performance.

Carpenter finds results which qualitatively correspond to our manager's behavior when the fund value is above the high-water mark. However, at lower fund values Carpenter's manager undertakes increasingly risky strategies. We illustrate this in Figure 5 by superimposing a graph similar to Carpenter's figure 3 on a stylized time slice from our Figure 4. 
Figure 5. Comparison of Risk Choices in Different Models I: Hodder \& Jackwerth, Merton, and Carpenter.

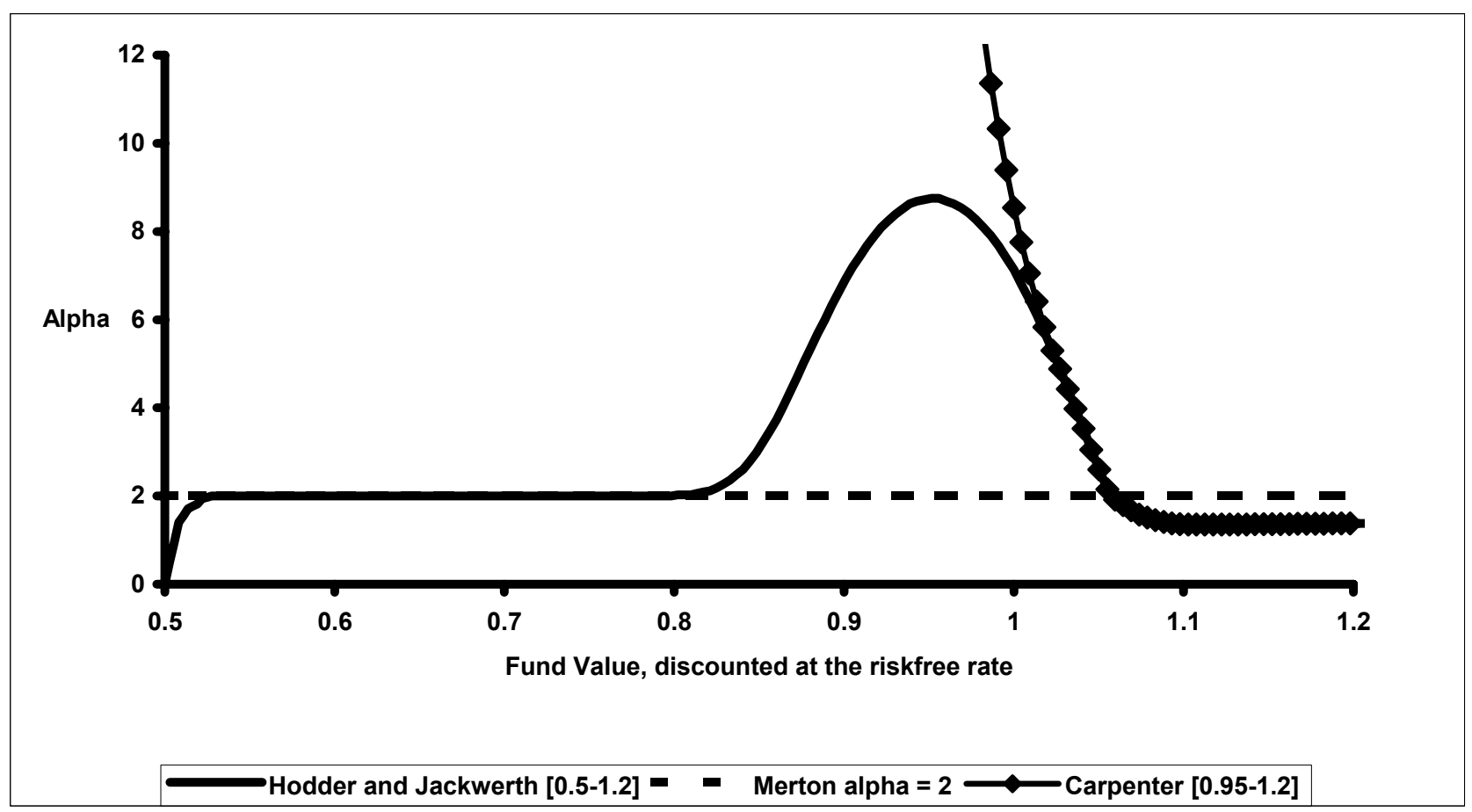

Carpenter describes her results as follows:

On the one hand, the convexity of the option makes the manager shun payoffs that are likely to be near the money. Under the optimal policy, the manager either significantly outperforms his benchmark or else incurs severe losses. Furthermore, in examples of optimal trading strategies, asset volatility goes to infinity as asset value goes to zero.

Yet the option compensation does not strictly lead to greater risk seeking. As asset value grows large, or if the evaluation date is far away, the manager moderates asset risk. For example, if the manager has constant relative risk aversion (CRRA), asset volatility converges to the Merton constant as asset value goes to infinity. In some situations, the manager actually chooses a lower asset volatility than he would if he were investing on his own, because the leverage inherent in his option magnifies his exposure to the asset volatility. (Page 2311)

The second paragraph of Carpenter's description corresponds very well to the behavior of our manager for relative high fund values. However, her manager behaves very differently from ours as fund value drops below the strike of the incentive option. Her manager continues to increase volatility as the fund value declines and there is no limit to this behavior since it is 
costless to the manager. On the other hand, our manager moderates volatility and gradually reduces risk to the level prevailing in Merton Flats. This difference in behavior is induced by our manager owning a fractional share in the fund which makes is very expensive for a risk averse manager to increase risk without limit. Parenthetically, even if the manager didn't explicitly own a fractional share $(\mathrm{a}=0)$, having a percentage fee based on the (terminal) value of funds under management $(b>0)$ generates similar results.

The liquidation boundary and the extent of severance compensation also play important roles in our model whereas Carpenter doesn't have a knockout barrier. This aspect of the analysis is partially examined in Goetzmann, Ingersoll, and Ross (GIR). That paper has a fee structure that is similar to ours (except for no explicit managerial ownership) as well as a liquidation boundary. In most of their paper, the hedge fund's investment policy is fixed. However, in Section IV they briefly explore an extension with the state space (measuring fund value) split into multiple regions, where different volatilities could be chosen by the manager. GIR use an equilibrium pricing approach with a martingale pricing operator based on the attitudes of a "representative investor" in the hedge fund. Hence, they can't directly address choices based on managerial utility. However, they are able to examine volatility choices which maximize the capitalized value of fees (performance plus annual) earned by the fund.

In that context, they examine two alternative cases (GIR, p. 1708). With no lower liquidation boundary, they find that "the volatility in each region should be set as high as possible if the goal is to maximize the present value of future fees." When they have a liquidation boundary, GIR find that "volatility should be reduced as the asset value drops near the liquidation level to ensure that liquidation does not occur." They also point out that "this conclusion is inconsistent with that of Carpenter (2000) in which volatility goes to infinity as asset value goes to zero." 
Clearly the knockout boundary plays a vital role. Carpenter doesn't have such a boundary (or managerial share ownership). Hence, at low asset values her manager is motivated only by the probability of getting back into the money prior to the evaluation date. The further out-of-the-money and the shorter time to maturity, the more the manager is willing to gamble. In contrast, GIR have a boundary at which fees go to zero. If the objective is to maximize fees, such a boundary is to be avoided, and this drives their result that volatility should be decreased as asset values approach the boundary. In effect, this is the result in our Figure 2 where a penalty imposed at the lower boundary causes the manger to reduce alpha (and volatility) as the fund value declines near the boundary. ${ }^{7}$

An important but perhaps subtle issue in the GIR model is the timing of performance fees. In GIR, such fees are earned continuously whenever the fund value reaches the high-water mark. In our model as well as Carpenter's, such fees are earned only on an evaluation date. This difference means that GIR's manager can never be deep in-the-money. Similarly, their manager can't lose an accrued incentive fee by falling out-of-the-money prior to an evaluation date. Hence, the GIR manager would always want to increase volatility as the fund value moves further away from the liquidation boundary. This serves to emphasize the role of timing in performance measurement. If performance evaluations are quarterly or annual, then the sort of behavior seen on the upside of Gambler's Ridge and beyond in Figures 3 and 4 is more realistic than GIR's continuously increasing volatility.

\footnotetext{
${ }^{7}$ In the continuous time limit of our model, it would always be possible for the manager to avoid hitting the boundary by switching completely into the riskless asset just before reaching the boundary. If there is any penalty associated with hitting the boundary, this behavior will obtain. On the other hand, if the manager is indifferent between continuing to manage the fund and hitting the boundary, we should observe the constant-alpha Merton result approaching the boundary. In either case, Gambler's Ridge and the Hill of Anticipation would vanish. In other words, these features are characteristics of the discrete-time nature of our model. Arguably, such features are realistic in the sense that continuous adjustments of the fund's portfolio would be impractical - e.g. due to transactions costs.
} 
Another related paper is Basak, Pavlova, and Shapiro (BPS). That paper examines the use of benchmarking to control the risk taking behavior of a money manager. The manager maximizes expected utility with respect to a terminal payoff function and exercises continuous control of the investment process. One version of their model examines optimal behavior with a single risky plus a riskless asset and generates results which can be fairly readily compared with ours.

Figure 6 illustrates the GIR and BPS results compared with ours and with Merton's. As discussed above, GIR's liquidation boundary and incentive structure with continuous earning of performance fees results in volatility being optimally zero at the knockout boundary and then increasing as the fund value rises. Their paper doesn't examine this situation graphically, but we illustrate the qualitative result at the left-hand side of Figure 6. 
Figure 6. Comparison of Risk Choices in Different Models II: Hodder \& Jackwerth, Merton, GIR, and BPS.

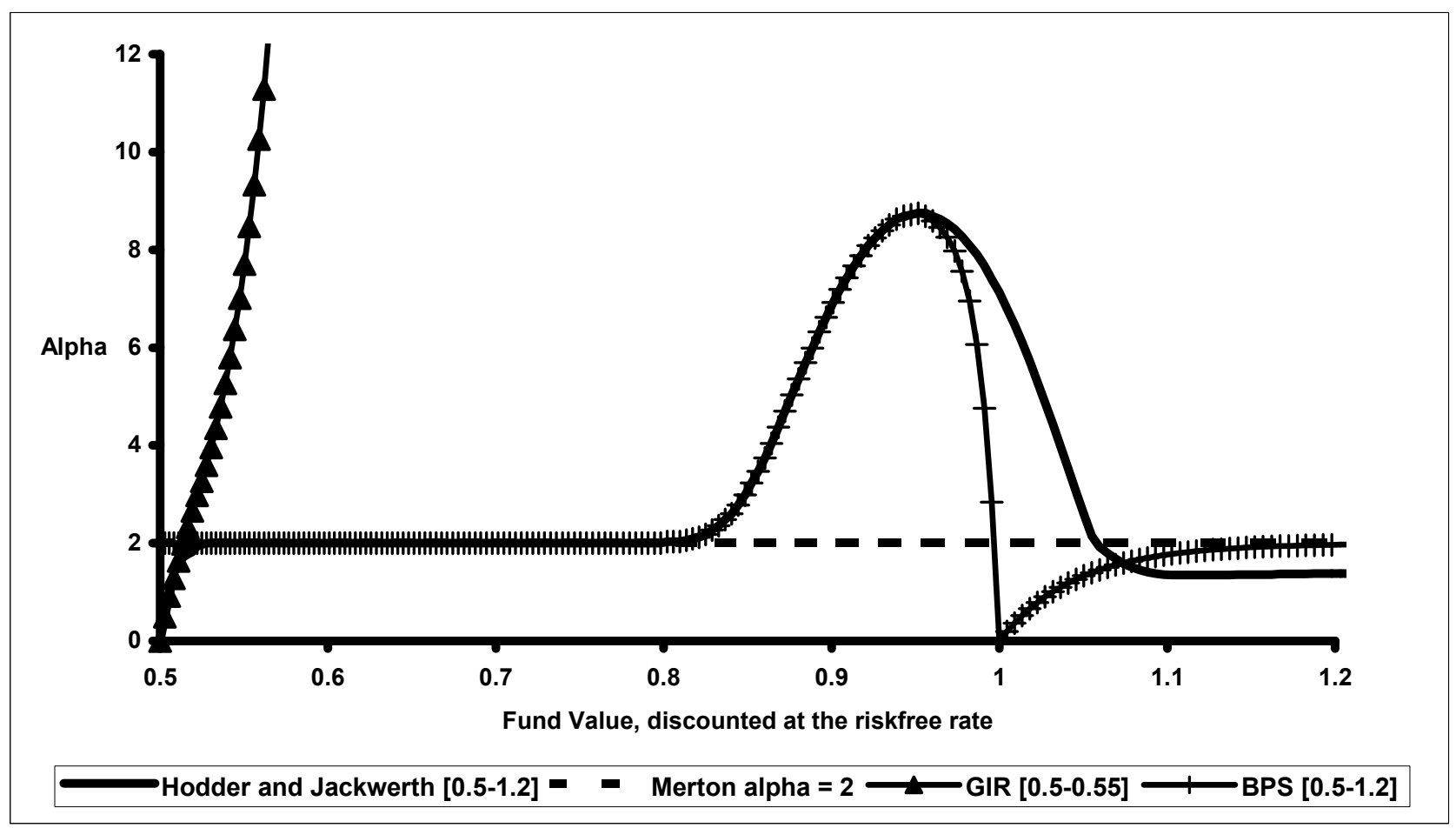

Our illustration of BPS results in Figure 6 is based on their figure $1 a^{8}$. First of all, BPS does not have a knockout boundary; and consequently, they don't get the types of boundary induced behavior (depending on the severance compensation structure) that occur in our model or in GIR. Instead, the BPS manager optimally pursues a Merton Flats strategy toward the left of Figure 6. This is because their manager's compensation in that region is effectively a fractional share. As fund value increases toward 1.0 (our high-water mark $\mathrm{H}_{0}$ ), the portfolio weight in the risky security rises $^{9}$ then dives dramatically to zero before rising gradually back to a Merton

${ }^{8}$ In their model, the benchmark is risky. An example would be the S\&P 500. Consequently, it's possible for their manager to follow a strategy which is either more or less risky than the benchmark. In the current version of our model, the high-water mark is known and it's not possible to follow a less risky strategy than setting alpha to zero (investing completely in the riskless asset). Hence, BPS figure $1 \mathrm{~b}$ is not applicable to our situation.

${ }^{9}$ However, the exact shape of this Option Ridge (our terminology) in BPS will depend on the parameter choices and can differ from our model. 
Flats strategy for high fund values. Differences in their manager's behavior in this region as compared with ours or Carpenter's are due to differences in the compensation structure.

BPS is attempting to model both implicit and explicit incentives for managerial performance. The explicit incentive comes from making the manager's compensation proportional to terminal fund value (assets under management in their terminology). This has the same effect as managerial share ownership and (absent other incentives) leads to a Merton Flats strategy. The implicit incentive comes from capital inflow or outflow in response to, respectively, good or poor performance. Performance is measured in their model relative to a benchmark. If managed returns at time $\mathrm{T}$ exceed those of the benchmark by a specified threshold amount (which can be positive, negative or zero), then capital flows into the fund. For comparison purposes, we set the threshold amount to zero and align their benchmark with our high-water mark at $\mathrm{H}_{0}=1.0$.

BPS model fund flow by adjusting the terminal fund value using a multiplier which takes on just two values -- $f_{L}<1$ for poor performance and $f_{H}>1$ when performance is good. Using our notation of $\mathrm{X}_{\mathrm{T}}$ for terminal fund value and $\mathrm{W}_{\mathrm{T}}$ for the manager's payoff, the BPS compensation structure is equivalent to:

$$
W_{T}=f_{L} X_{T}+\left(f_{H}-f_{L}\right) X_{T} 1_{\left\{X_{T} \geq H_{0} e^{r T}\right\}}
$$

The indicator variable takes on the value one in good performance states, where $\mathrm{X}_{\mathrm{T}}$ equals or exceeds what corresponds to our high-water mark. The BPS manager's compensation as portrayed in (9) is effectively a partial share of fund value plus a binary "asset or nothing" call option struck at the high-water mark. There are clear similarities between this compensation structure and our manager's payoff in equation (5) when she doesn't hit the liquidation boundary prior to date $\mathrm{T}$. In both cases, the manager has a partial share plus an incentive option. 
There is also a very important difference between (5) and (9). The incentive option for our manager is a standard call option struck at the high-water mark. If at date $\mathrm{T}$ that option is exactly at-the-money, it would add nothing to our manager's compensation. In contrast, the binary option in (9) has an at-the-money value of $\left(f_{H}-f_{L}\right) H_{0} e^{r T}$. In other words, the incentive structure of equation (9) implies a jump in the manager's compensation when performance just reaches the benchmark. ${ }^{10}$ That jump is what causes the BPS manager's optimal alpha in Figure 6 to dive to zero when fund value touches 1.0 (the strike price). In effect, that jump is sufficiently valuable to the manager that she chooses to "lock-in" the at-the-money position and hold it until date T. ${ }^{11}$ With higher fund values above the strike price, the BPS manager's risk taking heads back toward a Merton Flats strategy, as in our model as well as Carpenter's.

Comparison of these models highlights the importance of seemingly minor changes in the manager's compensation structure. For example, whether or not the manager has a share position as well as an incentive option can substantially mitigate risk taking behavior - compare our results and those of BPS with Carpenter. The nature of the incentive option (e.g. plain vanilla call versus binary asset-or-nothing) can make a substantial difference. We're inclined to believe that the BPS structure is too simple for modeling the capital flow in response to performance. However, it suggests that explicitly building binary options into performance incentives can lead to dramatic shifts in risk taking. On the other hand, inducing active managers to lock-in on a benchmark months before an evaluation date may not be that desirable. We also get the message that knockout barriers as well as the frequency of evaluation can have dramatic effects. In summary, there is a lot to be seen in this relatively simple comparison. Our Figure 4

10 In the next section, we will examine fund outflow in our own model in response to poor performance. Our structure is different from BPS and the effects on managerial behavior are rather moderate.

11 Presumably how far from maturity the manager would lock-in an at-the-money position depends on the parameters, including the size of the jump and the manager's risk aversion. In BPS figure 1a, the time to maturity is 2.4 months, so lock-in can hypothetically continue for a substantial period of time. 
may not depict the "whole elephant," but it does illustrate how managerial behavior can vary dramatically in different parts of the state space.

\section{Endogenous Liquidation}

The model developed in Section I used a prespecified liquidation boundary. This is a convenient simplification for a more complex reality in which the shutdown decision is endogenous and may depend on multiple factors. We will consider several of these scenarios in turn. For example, GIR suggest that fund liquidation results from outside investors withdrawing their funds in response to poor fund performance. Brown, Goetzmann, and Ibbotson (1999) indicate a belief that funds are terminated because it appears unlikely that performance will reach the high-water mark (presumably within a "reasonable" time frame). This later scenario is clearly a management decision and forces the outside investors to switch to another fund, resetting their high-water mark and forgoing the possibility of gains in the current fund without triggering incentive fees. Fung and Hsieh (1997, p. 297) point out the possibility that relatively poor performance may trigger fund outflow which is sufficiently large that "assets shrink so much that it is no longer economical to cover the fund's fixed overhead and the manager closes it down." They also mention the possibility that a young fund with good performance may go unnoticed, the managers get impatient, close down the fund, and return to trading for a financial institution.

These are all plausible scenarios, although it seems appropriate to view shutdown as a managerial decision which may be triggered by a large-scale investor withdrawal as well as other considerations. To the extent that managers have attractive outside opportunities and that covering fixed costs is an issue, a shutdown may well occur before outside investors would prefer - given the induced reset of their high water mark at a different fund. In this section, we explore the possibility of a decision by management to shutdown the fund using a relatively 
simple structure for the manager's payoff at this endogenous self-liquidation boundary. If the manager chooses to shutdown the fund at time $\tau$ at some $\mathrm{X}$ level above $\Phi_{\mathrm{t}}=0.5 \mathrm{H}_{0} \mathrm{e}^{\mathrm{rt}}$, she receives at maturity:

$$
\mathrm{aX} \mathrm{e}^{\mathrm{r}(\mathrm{T}-\tau)}+\mathrm{b}(1-\mathrm{a}) \tau \mathrm{X} \mathrm{e}^{\mathrm{r}(\mathrm{T}-\tau)}+\mathrm{L}(\mathrm{T}-\tau) \quad \text { for } 0 \leq \tau \leq \mathrm{T}
$$

where $\mathrm{L}$ represents an annual compensation rate which is independent of the fund value. The first two terms of (10) indicate that the manager recovers her share of the fund (aX) plus a prorated fraction of the management fee (with no incentive payment). These two amounts are invested for the time remaining until $\mathrm{T}$ at the riskless rate $\mathrm{r}$, since the manager no longer has access to the fund's investment technology after shutdown. She also earns L prorated over the time remaining until $\mathrm{T}$. One could think of $\mathrm{L}$ as representing what the manager could earn by going to work for a financial institution as suggested by Fung and Hsieh (1997).

We have included a prorated management fee in (10) based on the notion that this fee is intended (roughly) to cover operating costs and has been "earned" by operating the fund up to time $\tau$. What largely motivates the manager to keep the fund alive are the possibility of earning an incentive by exceeding the high-water mark and the ability to manage her own share using the fund's higher return technology. If $\mathrm{L}$ is large enough to offset those effects, she will choose to shutdown the fund below Option Ridge and potentially well above $\Phi_{t}$. This is illustrated in Figure 7 using an L value of 0.015 (1.5\% of the fund's initial asset value). 
Figure 7. Optimal Alpha Surface with Incentive Option and with Share Ownership by the Manager. Also, the Manager has the Option to Shutdown the Fund at her Discretion.

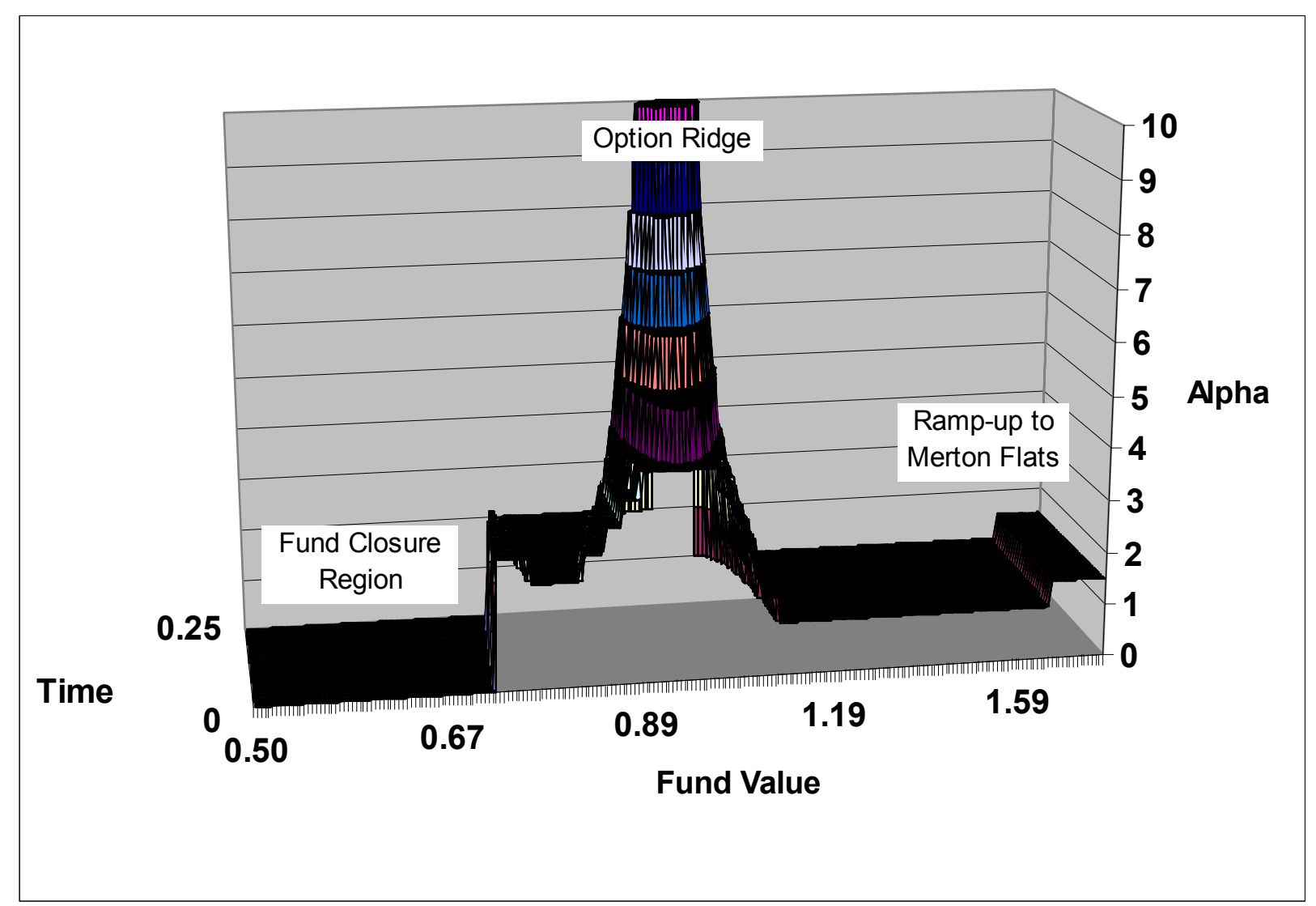

Intuitively, the probability of reaching the high-water mark becomes very small below Option Ridge and essentially disappears as an influence on the manager's decisions. There, she trades off the expected premium (above $r$ ) for managing her own share in the fund versus receiving external compensation at the annual rate $\mathrm{L}$. If $\mathrm{L}$ is sufficiently small, the manager will not voluntarily choose to shutdown and must be forced to liquidate at $\Phi_{t}$.

An alternative interpretation of (10) is that $b$ represents a percentage management fee net of operating costs and $\mathrm{L}$ is a fixed annual component of those operating costs. From that perspective, L represents an annualized opportunity cost savings from shutting down the fund -- 
along the lines suggested by Fung and Hsieh (1997). Realistically, L may well be a combination of cost savings plus an external employment opportunity.

The comments of GIR as well as Fung and Hsieh (1997) suggest that fund outflow in response to poor performance may be an important contributing factor to the shutdown decision. To gain some intuition on this possibility, we replace $X_{t}$ with $e^{-r t} X_{t}^{2}$ as the asset value for calculations at nodes below the high-water mark. ${ }^{12}$ Since our initial high-water mark is at $\mathrm{H}_{0}=1.0$, this transformation compounds the reduction of asset values as we move lower in the grid. For example at time $\mathrm{t}=0.25$, a $20 \%$ loss via poor performance is accompanied by an additional fund outflow amounting to $21 \%$ of the remaining assets. The combined effect is that assets drop to $(0.80)(0.79)=0.63 .13$

Interestingly, this modeling of fund outflow has a rather modest impact on the manager's shutdown decision. Below the high-water mark at maturity, replacing $\mathrm{X}_{\mathrm{T}}$ with $\mathrm{e}^{-\mathrm{rt}} \mathrm{X}_{\mathrm{T}}{ }^{2}$ effectively increases the exponent of the manager's utility function in equation (4) and thus increases the manager's risk aversion in that region of the state space. At earlier dates, this mitigates slightly the manager's gambling behavior on the lower side of Option Ridge; however, the most obvious effect is to lower the level of Merton Flats below Option Ridge. If the manager is choosing to shutdown some distance below Option Ridge (as in Figure 7), this causes her to marginally shift the closure point upward toward the lower edge of Option Ridge. If she is already shutting down the fund at the lower edge of Option Ridge, the fund outflow has almost no effect since the level of a (potential) Merton Flats below that shutdown level becomes irrelevant.

\footnotetext{
12 We chose to discount in order to penalize any performance that does not even earn the riskfree rate.

13 To avoid creating path dependence, we treat fund inflows and outflows symmetrically which ignores the possibility that inflows could have a differing high-water mark. For purposes of this illustration, that treatment seems innocuous.
} 
To summarize, the fund's cost structure and the manager's external opportunities appear to play important roles in her decision whether or not to shut down the fund. With our model's structure, a relatively modest external opportunity and/or cost savings can induce her to shut down below Option Ridge and well above the prespecified liquidation boundary. The risk of fund outflow effectively increases the manager's risk aversion in the lower portion of the state space but has little effect on her shutdown decision. Under such circumstances, outside investors experience a pattern of heavy gambling along Option Ridge with fund closure at perhaps only slightly lower asset values. This could be described as "heads the manager wins a performance incentive, tails outside investors have to find a new fund with their high-water mark reset to their detriment." That description sounds rather unappealing from the perspective of an outside investor but serves to illustrate the importance of being able to address the manager's optimal actions in an American Option framework.

\section{Managerial Effort}

Presumably, outsiders invest in a hedge fund because they believe the manager has an expertise that they can't replicate for themselves (or that replication is too costly). In previous sections, we modeled the manager as working with equal effort and skill at all grid points where the fund was in operation. We now consider the possibility that the manager has some control over the effort (and skill) she uses in managing the fund. We model this by assuming that she can enhance $\mu$ (the expected return of the risky investment technology) via expending more effort. ${ }^{14}$ However, expending effort reduces her utility.

14 Alternatively, we can model her effort as reducing the volatility $(\sigma)$ of the risky process. Altering $\sigma$ affects both the drift and volatility of the $\log X$ process, whereas altering $\mu$ affects just the drift. However, the qualitative effects are similar. 
We model this situation using $\psi$ to denote the level of effort expended. We use $\psi=0$ to denote the low effort level and increase $\psi$ in steps of 0.01 to a maximum of 0.02 (high effort level). The enhanced drift for the risky investment technology becomes $\mu+\psi$, and the manager's indirect utility function takes on the modified form of:

$$
\mathrm{G}(\mathrm{X}, \psi, \mathrm{t})=\mathrm{E}[\mathrm{G}(\mathrm{X}, \psi, \mathrm{t}+\Delta \mathrm{t})]-0.5 \mathrm{~g} \psi^{2}
$$

where $\mathrm{g}$ is a parameter that scales the manager's aversion to effort.

At each grid point, the manager jointly chooses $\alpha$ and $\psi$ to maximize her indirect utility (G). Previously, we had a discrete set of alpha values that allowed us to calculate a matrix of probabilities (a probability vector for each potential alpha value) that was the same for all grid points. Now, we change that matrix to have a probability vector for each possible combination of $\alpha$ and $\psi \cdot{ }^{15}$ Our augmented probability matrix is again the same throughout the grid. Hence, we employ the same basic procedure as previously and select the highest indirect utility from the set calculated using each of the probability vectors. We denote that value as the optimal $\mathrm{G}(\mathrm{X}, \psi, \mathrm{t})$ as we loop backward through time. We also record the optimal alpha and psi values for each grid point. For modest numbers of effort levels, this augmented procedure is not particularly onerous. Using three possible effort levels, there are three times as many probability vectors as previously. However, our procedure can easily handle the increased computation. ${ }^{16}$

\footnotetext{
${ }^{15}$ We simply calculate the probabilities of reaching the various subsequent grid points using the appropriate drift and volatility for each combination of $\alpha$ and $\psi$.

16 We have experimented with up to ten effort levels. This provides more refinement, but the overall qualitative results are much the same as with three effort levels.
} 
Figure 8: Optimal Alpha Surface with Standard Parameters plus a Choice of Three Effort Levels. Manager does not have a Shutdown Option.

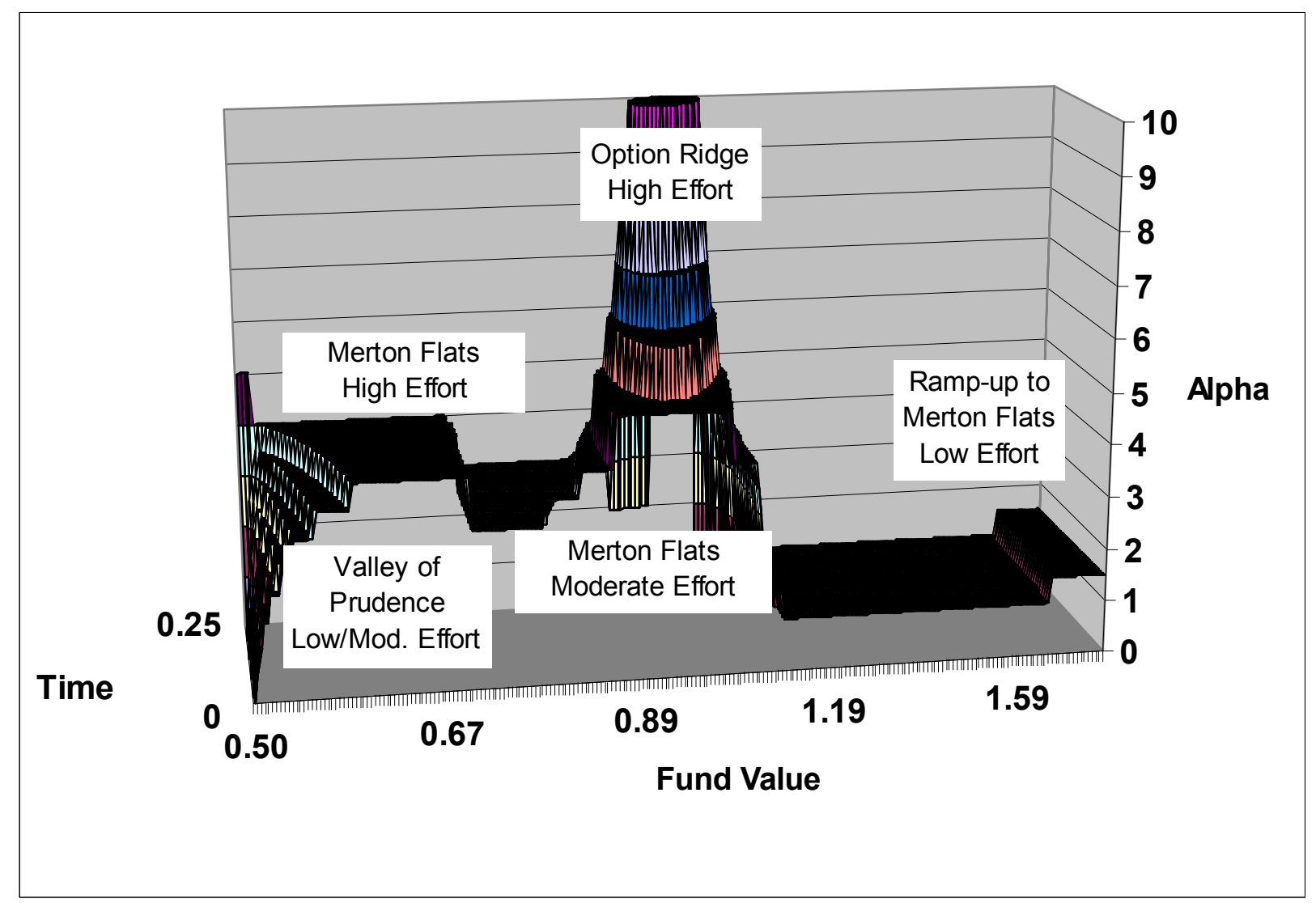

We use for our results an effort aversion coefficient of $g=2500$. Figure 8 displays typical results for the situation where the fund is liquidated at a prespecified barrier (one-half the high-water mark) as in Section II. We observe that the manager expends little effort at relatively high $\mathrm{X}$ values. These are states where she expects a relatively high terminal payoff and incremental income is less valuable for her utility than in low $\mathrm{X}$ states. Hence, she is less willing to expend effort in high $\mathrm{X}$ states. By making effort more beneficial or less costly (in terms of reduced utility), we can induce the manager to increase her effort level; but it still remains relatively low in states with high $\mathrm{X}$ values. On the other hand, she expends greater effort along 
Option Ridge and approaching Gamblers Ridge. These are also locations where she chooses high alpha values. As a somewhat loose generalization, she tends to exert maximum effort to get her incentive option into the money and to avoid liquidation.

Compared with Figure 4, the optimal alpha levels are higher below Option Ridge except for the lower portions of the Valley of Prudence -- where the manager is trying to avoid hitting the liquidation boundary by choosing very low alpha values. Alpha values are the same above Option Ridge in both figures. This is consistent with the manager expending low effort $(\psi=0)$ in Figure 8, while we have $\psi=0$ in Figure 4 by construction. Option Ridge is wider, indicating higher alpha values on the shoulders of that ridge. Intuitively, positive psi values increase the Sharpe Ratio for the risky technology and make greater investment (larger alpha) more attractive. This motivation is very clear in the Merton Flats region below Option Ridge. In Figure 4, the optimal alpha for that region is 2 . In Figure 8, the optimal alpha increases to 3 with moderate effort $(\psi=0.01)$ and to 4 with high effort $(\psi=0.02)$. Using equation (8) with $\mu$ replaced by $\mu+\psi$, one can readily see that these are the appropriate optimal alpha values conditional on those levels of effort.

We now add the possibility of the manager choosing to shutdown the fund using the same modeling structure as in Section IV. This is illustrated in Figure 9 using an L value of 0.015, which is large enough to induce a shutdown somewhat below Option Ridge. This results in her choosing to shutdown shortly after encountering the lower region of Merton Flats with an optimal alpha of $4 .{ }^{17}$ Above that endogenous shutdown level, Figures 8 and 9 are almost identical, indicating virtually the same alpha and effort choices.

17 We can shift the shutdown level up and down by altering L. 
Figure 9: Optimal Alpha Surface with Standard Parameters plus a Choice of Three Effort Levels. Here the Manager has the Option to Shut Down the Fund at her Discretion.

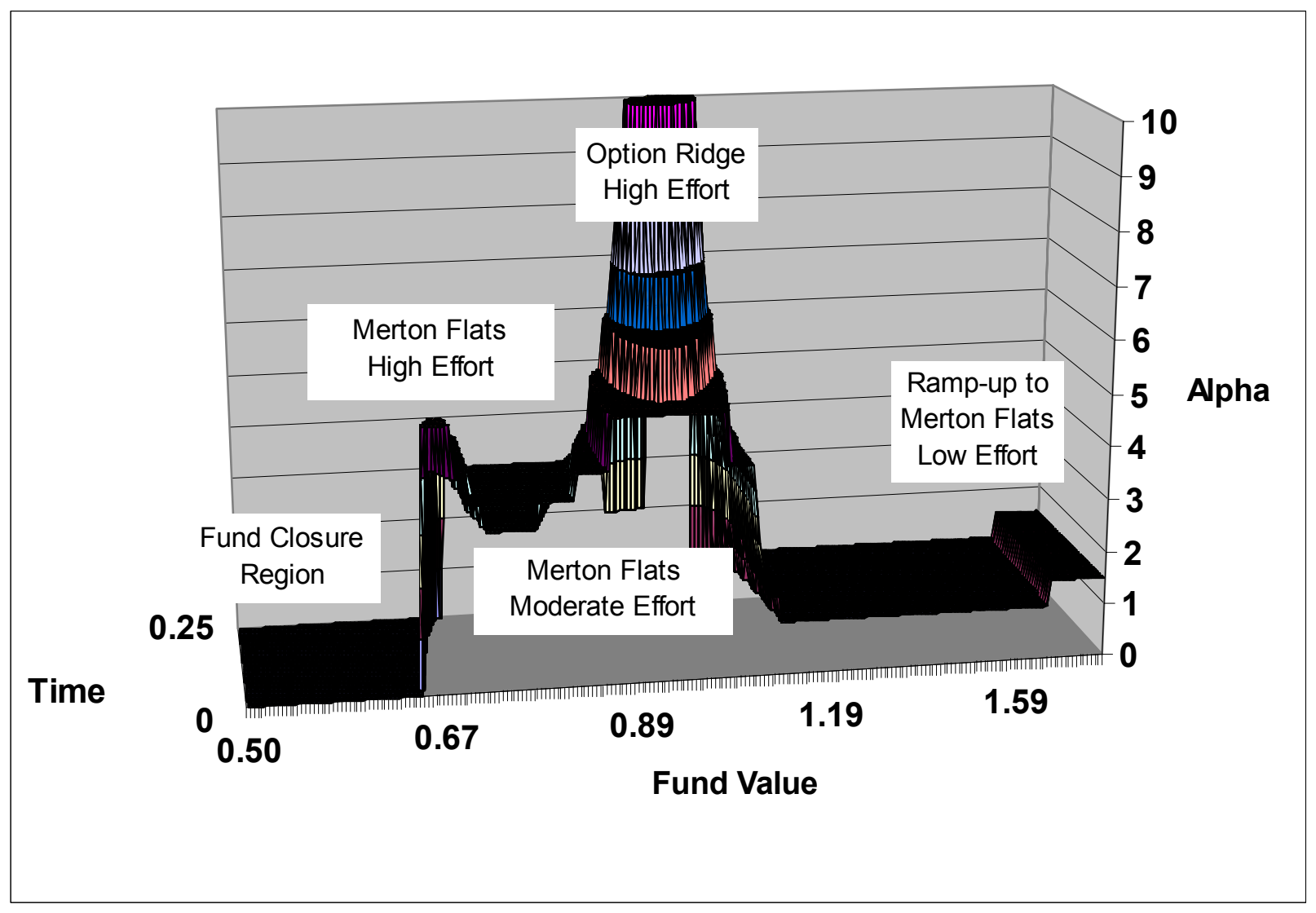

As in Section IV, the manager's ability to voluntarily shutdown damages outside investors by forcing them to reset their high-water marks at other funds. However, the increased alpha value (4) in the high-effort portion of Merton Flats causes the manager to lower slightly the endogenous shutdown level as compared with that in Figure 7.

Including effort as a managerial choice variable yields some interesting results; but ones that are intuitively reasonable after some reflection. We see increased effort only on and below Option Ridge. The manager becomes something of a "slacker" when things are going well. Admittedly, the model is simplified; however, this result suggests that the typical hedge-fund incentive structure may not elicit intensive managerial effort at high $\mathrm{X}$ levels. It is also 
interesting that increased effort goes together with higher alpha values rather than resulting in a tradeoff between the two. Thus, one needs to exercise some caution before inferring whether a relatively high alpha is the result of just gambling or in response to enhanced upside probabilities resulting from extra effort by the manager.

\section{Concluding Comments}

The major thrust of this paper is to explore the optimal behavior of an expected utility maximizing hedge-fund manager who can control the fund's investments. Controlling those investments implies controlling the stochastic process for fund value. An underlying theme of the paper is developing a methodology for valuing payoffs (derivatives) based on such a controlled process. We feel this is a research direction that warrants attention. Our manager does not follow anything close to a constant risk strategy; and hence, the stochastic process followed by fund value is far from exogenous.

Exploring the effects of a typical hedge-fund compensation contract as well as the implications of differing shutdown alternatives, we find a range of rich and interesting managerial behavior. We also find that seemingly slight adjustments in the compensation structure can have dramatic effects on managerial risk taking. For example, even a relatively small penalty for hitting the lower boundary can dramatically reduce risk-taking in the lower portions of the state space (compare Figures 1 and 2). Whether or not the manager has an ownership stake has major implications for risk-taking behavior, as does the precise nature of any incentive options.

This is again illustrated in Section III (see Figures 5 and 6), where we examine results from recent papers by Carpenter (2000), Goetzmann, Ingersoll, and Ross (2003), and Basak, Pavlova, and Shapiro (2003). Seemingly slight differences in their compensation structures 
result in striking differences in managerial behavior. Although we can explain these results using our model and put them into a more general context, their divergence illustrates that one needs to be cautious with generalities about managerial behavior. Seemingly minor additions to the model can have major implications.

Allowing the manager to voluntarily shutdown the fund adds an American-style option to the analysis. Our methodology can readily handle this situation, and it adds an interesting aspect of managerial discretion. Our analysis suggest that two key drivers in the shutdown decision are the manager's outside opportunities and it being very unlikely that fund value will get above the high-water mark by the evaluation date. Fund outflow may accelerate the shutdown decision but appears to play a secondary role, at least with our modeling structure. Being below Option Ridge can be viewed as a necessary condition for the manager to voluntarily liquidate the fund. However, it's possible that the manager chooses to shutdown at a fund value well above what outside investors would prefer.

Allowing the manager to enhance the fund's Sharpe Ratio via increased effort adds another interesting dimension to the analysis. One striking result is that high effort tends to go together with relatively high risk taking. This makes sense because the effort enhances the Sharpe Ratio, which makes greater risk taking more attractive. A second potentially important result is that standard hedge fund compensation contracts appear to not provide much incentive for high effort levels when the fund is doing well. Our model is definitely simplified, but such issues clearly warrant further attention.

Similar statements could be made regarding our analysis of the shutdown option, the manager's severance compensation, and indeed her basic compensation structure. We certainly do not feel that we have the final answer on these issues. Rather, we feel that the methodology introduced in this paper has allowed us to identify a number of interesting issues which warrant further research. 


\section{Appendix: Numerical Procedure}

We discretize the continuous problem onto a finite-difference grid which spans across fund value $[\Delta(\log \mathrm{X})=\mathrm{constan} \mathrm{t}]$ and time $[\Delta \mathrm{t}=$ constant $]$. We choose the value dimension with equal $\log$ spacing and with the initial level $\mathrm{X}_{0}$ on the grid. It is convenient to have the grid points for the $\mathrm{i}^{\text {th }}$ fund level increase over each time step at the riskfree rate $\mathrm{e}^{\mathrm{r} \Delta \mathrm{t}}$. This choice stems from the fact that in the limiting case where the manager chooses $\alpha=0$ and only invests in the riskfree asset, the value process will still reach a regular grid point. Thus, the grid structure will not prevent the manager from switching to the riskfree strategy. Maintaining this structure for the lower boundary implies having $\Phi_{t}=\Phi_{0} e^{r t}$.

Given the grid, we calculate the terminal payoff for the manager based on her compensation scheme and the realization of the optimally controlled fund value process at time T. We also compute the associated utility at each of those terminal grid points. Our next task is to calculate the indirect utility function at earlier time steps as an expectation of future indirect utility levels. We thus need the probability of moving from one fund value level at time to another value level at time $\mathrm{t}+\Delta \mathrm{t}$. These probabilities depend on $\alpha(\mathrm{X}, \mathrm{t})$ since the choice of alpha determines the process for $\mathrm{X}$ over the next time step.

For a given alpha, the log change in $\mathrm{X}$ is normally distributed with mean

$$
\mu_{\alpha, \Delta t}=\left[\alpha \mu+(1-\alpha) r-\frac{1}{2} \alpha^{2} \sigma^{2}\right] \Delta t
$$

and volatility $\sigma_{\alpha, \Delta t}=\alpha \sigma \sqrt{\Delta t}$. Recall that we need these log changes in $\mathrm{X}$ to fall on grid points. To accomplish this, we approximate the normal distribution of log changes in the following manner. The possible $\log \mathrm{X}$ moves are $r \Delta t+i \Delta(\log X)$. The first term in that expression is due 
to the riskfree drift in the $\mathrm{X}$ grid. In the second term, we limit outcomes to lie on grid points indexed by $\mathrm{i}$, which is measured as an offset relative to the current grid point level. In our standard model, we let the offset $\mathrm{i}$ range from $-60, \ldots, 0, \ldots, 60$. For a given alpha, we calculate the probabilities based on the normal density times a normalization constant so that the computed probabilities sum to one:

$$
p_{i, \alpha, \Delta t}=\frac{\frac{1}{\sqrt{2 \pi} \sigma} E X P\left[-\frac{1}{2}\left(\frac{r \Delta t+i \Delta(\log X)-\mu_{\alpha, \Delta t}}{\sigma_{\alpha, \Delta t}}\right)^{2}\right]}{\sum_{j=-60}^{60} \frac{1}{\sqrt{2 \pi} \sigma} E X P\left[-\frac{1}{2}\left(\frac{r \Delta t+j \Delta(\log X)-\mu_{\alpha, \Delta t}}{\sigma_{\alpha, \Delta t}}\right)^{2}\right]}
$$

For a specified alpha value, these probabilities are identical at each grid point. This results from our choosing the $\log \mathrm{X}$ step size to be constant. We keep a table of the probabilities for different choices of alpha which we vary from $0,0.1,0.2,0.5,1.0,1.5,2.0,2.5,3,3.5,4,5,6$, $7,8,10$, to 20 . However, the ends of this range are problematic and can result in poor approximations to the normal distribution. For low alpha values, the approximation suffers from not having fine enough value steps. For high alpha values, the difficulty arises from potentially not having enough offset range to accommodate the extreme tails of the distribution.

To insure reasonable accuracy, we compare the standardized moments of our approximated normal distribution $\hat{\mu}_{j}$ with the theoretical moments of the standard normal, $\mu_{j}=1 \cdot 3 \cdot \ldots \cdot(j-1)$ for $\mathrm{j}$ even and $\mu_{j}=0$ for $\mathrm{j}$ odd. In particular, we calculate a test statistic based on the differences of the first 10 approximated and theoretical moments scaled by the asymptotic variance of the moment estimation - see Stuart and Ord (1987, p. 322): 


$$
\frac{1}{10} \sum_{j=1}^{10}\left(\frac{\hat{\mu}_{j}-\mu_{j}}{\frac{1}{n}\left(\mu_{2 j}-\mu_{j}^{2}+j^{2} \mu_{2} \mu_{j-1}^{2}-2 j \mu_{j-1} \mu_{j+1}\right)}\right)^{2} \text {, where we set } n=1
$$

After some experimentation, we discard distributions with a test statistic of more than 0.01 . For our standard model, this results in eliminating the distributions associated with the alpha level of 0.1 and the alpha levels greater than 10 . We finally have a matrix of probabilities with a probability vector for each alpha value in our remaining choice set.

We now commence stepping backwards in time from the terminal date T. At each grid point within a time step, we calculate the expected indirect utilities for all alpha levels and choose the highest as our optimal indirect utility, $\mathrm{J}(\mathrm{X}, \mathrm{t})$. We record that value and the associated optimal alpha for each grid point. This procedure for identifying the best alpha at each grid point is analogous to using a lookup table. In our situation, this has two advantages compared with using an optimization routine. For one, lookups are faster although coarser than optimizations. Second, a sufficiently fine lookup table is a global optimization method that will find the true maximum even for non-concave indirect utility functions. In such situations, a local optimization routine can get stuck at a local maximum and gradient-based methods might face difficulties due to discontinuous derivatives. We compute the indirect utility surface for all grid points within a time step and then loop backward in time through all time steps.

When implementing our backward sweep through the grid, we have to deal with behavior at the boundaries. The terminal step is trivial in that we calculate the terminal utility from the terminal wealth. The lower boundary is also quite straightforward. We stop the process upon reaching or crossing the boundary and calculate the utility associated with hitting the boundary at that time. For our basic model, the manager's severance pay is reinvested at the riskfree rate until time $\mathrm{T}$; and consequently, she receives $\mathrm{W}_{\mathrm{T}}=\mathrm{aX}_{\tau} \mathrm{e}^{\mathrm{r}(\mathrm{T}-\tau)}+0.5(1-\mathrm{a}) \mathrm{b} \tau \mathrm{H}_{0} \mathrm{e}^{\mathrm{rT}}$ for sure at the terminal date. In terms of a grid with indirect utilities, we are effectively copying terminal 
(indirect) utility values (one for each $\mathrm{X}_{\tau}$ and $\tau$ combination) into appropriate grid points below the liquidation boundary that can be reached by our normal approximation.

For the numerical implementation, we need an upper boundary to approximate indirect utilities associated with high $\mathrm{X}$ values. We use a boundary 600 steps above the initial X level. For grid points near that boundary, our normal approximation procedure will seek indirect utility values associated with points above the boundary. We deal with this by keeping a buffer of grid points above the boundary so that the expected indirect utility can be calculated by looking up values from such points. We set the terminal buffer values simply to the utility for the wealth level at that grid point. We then step back in time and use as our indirect utility the utility of the following date times a multiplier which is based on the optimal Merton solution. This allows for general utility functions but biases the results low. However, the distortion ripples only some 2050 steps below the upper boundary, affecting mainly the early time steps.

Although computationally somewhat intensive, the above numerical procedure is both intuitive and flexible. Moreover, it allows us to analyze situations that do not appear amenable to closed-form analytic solutions. Three aspects contribute to the performance of our approach. First, we use a finely spaced finite-difference grid to insure high resolution of the results. Second, we use the terminal distribution over each time step directly and approximate this normal distribution very accurately. Third, we use a fast and globally convergent grid search for the optimizations. The end result is a relative fast and very flexible approach for valuing potentially complex payoffs on a controlled process. 


\section{References}

Basak, Suleyman, Anna Pavlova, and Alex Shapiro (2003), "Offsetting the Incentives: Risk Shifting and Benefits of Benchmarking in Money Management," Working Paper 430303, MIT Sloan School of Management, April.

Basak, Suleyman, Alex Shapiro, and Lucie Teplá (2002), "Risk Management with Benchmarking," working paper, October.

Brown, Stephen J., William N. Goetzmann, and Roger G. Ibbotson (1999), "Offshore Hedge Funds: Survival and Performance, 1989-95” Journal of Business 72, 99-117.

Carpenter, Jennifer N. (2000), “Does Option Compensation Increase managerial Risk Appetite?” Journal of Finance 55, 2311-2331.

Fung, William and David A. Hsieh (1997), "Empirical Characteristics of Dynamic Trading Strategies: The Case of Hedge Funds," Review of Financial Studies 10, 275-302.

Fung, William and David A. Hsieh (1999), “A Primer on Hedge Funds,” Journal of Empirical Finance 6, 309-331.

Goetzmann, William N., Jonathan E. Ingersoll, Jr., and Stephen A. Ross (2003), "High-Water Marks and Hedge Fund Management Contracts," Journal of Finance 58, No. 4, 1685 1717.

Markowitz, Harry (1959), Portfolio Selection: Efficient Diversification of Investments, Cowles Foundation Monograph \#16 (Wiley 1959); reprinted with Markowitz's hindsight comments on several chapters and with an additional bibliography supplied by $\mathrm{M}$. Rubinstein (Blackwell 1991).

Merton, Robert (1969), Lifetime Portfolio Selection under Uncertainty: The Continuous Time Case, Review of Economics and Statistics 51, 247-257.

Merton, Robert (1974), On the Pricing of Corporate Debt: The Risk Structure of Interest Rates, Journal of Finance, 11, 449-470.

Mossin, Jan (1968), Optimal Multiperiod Portfolio Policies, Journal of Business 41, No. 2, 215229.

Ross, Stephen A. (forthcoming), "Compensation, Incentives, and the Duality of Risk Aversion and Riskiness," Journal of Finance.

Stuart, A., and S. Ord (1987), Kendall's Advanced Theory of Statistics, Vol. 1, $5^{\text {th }}$ ed. Oxford University Press, New York. 